\title{
MÉXICO: ¿SISTEMA PRESIDENCIAL O PARLAMENTARIO?
}

\section{Jorge CARPIZO}

RESUMEN: Haciendo un análisis y una valoración de las ideas expuestas por Juan Linz, Giovanni Sartori, Dieter Nohlen, Alonso Lujambio, Diego Valadés y Manuel Aragón, principalmente, el autor pondera la conveniencia de que en México el sistema presidencial actual transite a un sistema parlamentario. En el artículo se señalan tres aspectos que hay que tomar en cuenta para resolver la cuestión: la falta casi absoluta de controles de poder, así como del equilibrio de poderes en el sistema presidencial; el funcionamiento de un sistema de gobierno que opera en forma diversa según sea el sistema de partidos vigente; y la contradicción que existiría entre el principio de no reelección y la reelegibilidad del primer ministro en el sistema parlamentario. El autor concluye que a priori el sistema parlamentario no es mejor ni más democrático y se inclina por un sistema presidencial renovado, en donde exista un mejor equilibrio de poderes, lo que se lograría dando algunos controles adicionales al Legislativo, y dejando que el Ejecutivo solamente ejerza las facultades que la Constitución y las leyes le señalen.
ABSTRACT: By analyzing and evaluating the ideas put forward by Juan Linz, Giovanni Sartori, Dieter Nohlen, Alonso Lujambio, Diego Valadés and Manuel Aragón, the author weighs the convenience of the present Mexican presidential system being replaced by a parliamentary system. Three aspects which much be taken into consideration in resolving the matter are mentioned in the article: the almost complete lack in the presidential system of a control of power, together with a balance of power; the working of a government system that operates differently depending on the current party system; and the contradiction which would exist between the principle of no reelection and the re-eligibility of the Prime Minister under the parliamentary system. The author reaches the conclusion that a priori the parliamentary system is no better nor more democratic, and leans toward a renewed presidential system with a better balance of powers, which could be achieved by giving the Legislature some additional powers, and according the President only such powers as are conferred on him by Constitution and the laws. 
Los griegos en los tiempos antiguos solían preguntar al sabio Solón: “¿Cuál es la mejor Constitución?" Él solía contestar: "Decidme primero para qué pueblo y para qué época”.

Charles DE GAULLE, 1946

\section{PREOCUPACIONES RESPECTO AL SISTEMA DE GOBIERNO}

A. Existe actualmente preocupación o profunda preocupación por diversos temas político-constitucionales en algunos sectores de la sociedad mexicana. Uno de ellos se refiere al sistema de gobierno: si de nuestro presente sistema presidencial debemos transitar a uno parlamentario. Es decir, existe la inquietud real de conocer si nuestro sistema presidencial es el más adecuado para el México de hoy y para el de los años venideros.

¿Por qué existe esta preocupación o inquietud? En mi opinión porque en las últimas décadas: a) el equilibrio de poderes se ha inclinado decididamente en favor del Ejecutivo, b) el Poder Legislativo no ha ejercido muchas de sus facultades constitucionales, c) el presidente de la República ha realizado atribuciones metaconstitucionales que lo convierten en la columna vertebral de todo el sistema político, d) los pesos y contrapesos constitucionales no han operado y, e) las libertades y derechos de los mexicanos han quedado en ocasiones a la discreción del Poder Ejecutivo.

¿Es posible que resolvamos esos y otros problemas con un cambio al sistema parlamentario?

En los últimos diez años, dos de los más importantes países de América Latina - Argentina y Brasil— también se plantearon la mencionada posibilidad y por causas parecidas a las de México, las que se pueden sintetizar en el anhelo de mayores y mejores controles al Ejecutivo federal para alcanzar un verdadero equilibrio de poderes que fortalezca a los sistemas democráticos.

Esa discusión en Brasil fue muy importante. La Asamblea Constituyente de 1987, basada en el proyecto de reformas de la Comisión Arinos, se inclinaba por el sistema parlamentario. Empero, dicha asamblea ratificó el sistema presidencial, pero no en forma definitiva ya que las fuerzas políticas que se inclinaban por el régimen parlamentario no podían 
ser ignoradas. El artículo segundo transitorio de la Constitución brasileña de 1988 ordenó que el día 7 de septiembre de 1993, el electorado definiría a través de un plebiscito la forma y el sistema de gobierno de ese país: monarquía o república, sistema parlamentario o presidencial. El pueblo brasileño se decidió por las segundas posibilidades: república y presidencial.

En Argentina la reforma constitucional de 1994 también se inclinó por el sistema presidencial pero atenuado o con sujeción parlamentaria -en la expresión de Nogueira Alcalá- ${ }^{1}$ primordialmente con la creación, en el artículo 100 constitucional, de un jefe de gabinete de ministros, con responsabilidad política ante el congreso federal y cuyas principales facultades se relacionan con la administración general del país y los expedientes de los proyectos de ley.

En consecuencia, éste no es un tema fácil y lo vamos a comprobar en este ensayo; las discusiones que se realizaron en Argentina y Brasil nos lo confirman.

B. El mencionado profesor argentino nos recuerda ideas que son ciertas y muy extendidas: que el tipo de gobierno de un país no lo definen únicamente los preceptos constitucionales, sino que es necesario considerar también la "Constitución extrajurídica", la que se basa en prácticas, tradiciones culturales, actitudes y expectativas de los actores políticos, el sistema electoral y el régimen de los partidos políticos. ${ }^{2}$

El eminente constitucionalista Jorge Reinaldo Vanossi nos alerta con su habitual agudeza que:

En los sistemas constitucionales hay una regla de oro subyacente, no necesariamente escrita pero que se infiere de la propia estructura de equilibrio que suponen los sistemas de democracia constitucional, según la cual a todo acrecentamiento del poder debe corresponder un vigorizamiento de los controles, un mejoramiento de las garantías y un acentuamiento de las responsabilidades. Dicho con otras palabras: a más poder más control, mejores garantías y superiores responsabilidades. Esta regla, que exige un correlato entre los problemas de dimensionamiento del poder y los problemas de cualificación de las garantías que hacen al equilibrio de ese poder, está señalando la necesidad

1 Nogueira Alcalá, Humberto, "Los presidencialismos puros y atenuados. Los casos de Chile y la Argentina”, Boletín Informativo, Buenos Aires, año XIV, núm. 144, Asociación Argentina de Derecho Constitucional, 1998, p. 5.

2 Nogueira Alcalá, Humberto, op. cit., p. 3. 
de una equivalencia que si se rompe altera la funcionalidad del sistema y ésta entra en una pendiente. Es eso que los sociólogos llaman propiamente casos de anomia, en los cuales va gradualmente desapareciendo el marco de referencia, la sociedad se desencanta, se desmotiva, se desentiende. Hasta la suerte misma que pueda correr el sistema deja de interesarle y se termina en lo que los niños con su inocencia, pero con su gran y certera claridad dicen en dos palabras: todo vale. Es decir no hay ya marco de referencia o parámetro entre el bien y el mal, entre lo lícito y lo ilícito, entre lo permitido y lo prohibido. Estos son los procesos de deslegitimación que tienen por lo general un punto de arranque en el debilitamiento de los sistemas de garantías. ${ }^{3}$

Exactamente aquí se encuentra el gran problema del sistema presidencial mexicano: la falta casi absoluta en la realidad de controles y el desequilibrio colosal que se da entre los poderes en nuestro país, situaciones a las cuales me he venido refiriendo desde 1978, cuando se editó mi libro sobre este tema. ${ }^{4}$

\section{SISTEMAS DE GOBIERNO Y PARTIDOS POLÍTICOS}

A. Ahora bien, el sistema de gobierno, ${ }^{5}$ ya sea presidencial, parlamentario o semi presidencial, opera con la misma Constitución en forma muy diferente de acuerdo con el número real de partidos políticos que existen en ese país y en ese número influye determinantemente el sistema electoral.

Es decir, el funcionamiento de los poderes, específicamente del Ejecutivo y del Legislativo, asentado en la Constitución, operará en forma diversa según sea el sistema de partido o partidos políticos en esa sociedad. O sea, el sistema de gobierno es una estructura en la cual se desarrolla un proceso político que está en una muy buena parte marcado por el número de los partidos políticos y el sistema electoral.

3 Vanossi, Jorge Reinaldo, “El 'habeas data': no puede ni debe contraponerse a la libertad de los medios de prensa”, El Derecho, Buenos Aires, año XXXII, núm. 8580, Universidad Católica Argentina, 1994, p. 1.

4 Carpizo, Jorge, El presidencialismo mexicano, México, Siglo XXI, 1978.

5 Respecto a las características de los sistemas presidencial y parlamentario, véase Loewenstein, Karl, Teoría de la Constitución, Barcelona, Ariel, 1965, pp. 105-107. Carpizo, Jorge, "Derecho constitucional", Las Humanidades en el Siglo XX. El derecho, México, UNAM, 1976, pp. 120-121. Carpizo, Jorge, primera obra mencionada, p. 14. Duverger, Maurice, Instituciones políticas y derecho constitucional, Barcelona, Ariel, 1962, p. 319. 
Así, diferente funcionará ese sistema de gobierno, si hay bi o multipartidismo, un solo partido o un partido predominante. ${ }^{6}$

En México, por décadas, hemos conocido el sistema de un partido predominante o hegemónico, en el cual la abrumadora mayoría de los legisladores federales y locales pertenecían a ese partido del cual el presidente de la República es el jefe real. Este solo dato es más que suficiente para explicar entre nosotros la carencia de controles por parte del Poder Legislativo respecto al Ejecutivo y el notorio desequilibrio entre ellos.

Aún no está claro cómo quedará definido el nuevo sistema de partidos en México, pero actualmente al existir tres grandes partidos políticos y otros pequeños, y al no contar el PRI con la mayoría absoluta en la Cámara federal de diputados, estamos viendo cómo comienzan a ejercerse algunos de los controles que establece nuestra Constitución desde 1917, como es el caso del denominado "poder de la bolsa", que es tan importante.

En otras palabras, todavía no sabemos con precisión cómo operará en la realidad nuestra actual ley fundamental y su sistema presidencial con un sistema tripartito de partidos sumados a otros de tamaño pequeño.

B. A su vez, cualquier sistema presidencial funcionará muy diferente, dependiendo de si:

a) El presidente y la mayoría de los legisladores en las dos cámaras legislativas — donde existen dos- son del mismo partido.

b) En las dos cámaras legislativas el partido del presidente no cuenta con la mayoría legislativa.

c) El presidente y la mayoría de los legisladores en una de las cámaras legislativas pertenecen al mismo partido pero esa no es la situación en la segunda cámara. Aquí tiene relevancia si se trata de la cámara alta o de la baja. Esta es la situación que se presenta ahora en México, el presidente de la República y la mayoría de los senadores pertenecen al mismo partido, pero en la otra cámara — la de diputados, que es la más importante por sus facultades respecto al "poder de la bolsa" - ningún partido tiene la mayoría, pero una coalición de partidos diversos al del presidente puede configurarla.

En los Estados Unidos de Norteamérica actualmente, en las dos cámaras legislativas federales, la mayoría de los legisladores son del partido

6 Carpizo, Jorge, Derecho constitucional, cit., p. 124. 
contrario al del presidente Clinton. Claro está que ese sistema funciona en forma diversa a si la situación fuera la contraria de la señalada, pero las dos diferencias que entonces acontecen, son que los controles legislativos que indica la Constitución operan con mayor rigidez y con toda plenitud y el Ejecutivo está obligado a negociar mucho más con el Congreso y a tomar en cuenta a éste en forma tal que sea factible que logre sacar adelante su agenda legislativa. Negociación y más negociación, cuyo resultado es un mejor equilibrio entre los poderes.

C. En el sistema parlamentario acontece idéntica situación que en el presidencial. La operación real del sistema depende del número de partidos existentes en el país: dos, tres, cuatro o más y si el partido político que integra el gobierno cuenta o no con la mayoría de los legisladores en el Poder Legislativo, específicamente en la cámara baja.

En el sistema parlamentario clásico, el inglés, que realmente es bipartita, si uno de los partidos tiene la mayoría de los legisladores en la Cámara de los Comunes, entonces el primer ministro - que es una parte del Poder Ejecutivo- es el líder de ese partido y por ese carácter, por la disciplina de partido y porque los legisladores del partido mayoritario no desean elecciones anticipadas, el primer ministro tiene realmente el control del parlamento, ${ }^{7}$ o si se quiere, no existe ningún control del Legislativo respecto al Ejecutivo; ${ }^{8}$ situación que se atenúa si ninguno de los dos grandes partidos consigue la mayoría en la Cámara de los Comunes y resulta necesario coaligarse con un tercer partido pequeño para conseguirla. Entonces, la negociación real se da entre los dos líderes de los partidos que se coaligan para poder formar un gobierno y dentro del marco de la fuerza política que sus partidos tienen en esa cámara.

7 Jennings, W. Ivor, The British Constitution, Londres, University of London Press, 1966, pp. 179-184. Wade, E.C.S. y Phillips, G.G, Constitutional Law, 7a. ed., corregida con A. W. Bradley, Londres, Longmans, 1966, pp. 95, 102, 123, 125, 126, 191 y 192. Carpizo, Jorge, Lineamientos constitucionales de la Commonwealth, México, UNAM, 1971, pp. 37-45.

8 Duverger, Maurice, La Monarchie Republicaine, París, Editions Robert Laffont, 1974. A partir de la página 109 se refiere al gran poder que tiene el primer ministro inglés quien encabeza una monarquía republicana más eficaz que la de los Estados Unidos de Norteamérica. Actualmente en Gran Bretaña — sostiene- las elecciones legislativas se han convertido en elección por el primer ministro, el cual posee una gran autoridad sobre el parlamento a través de su partido mayoritario y la disciplina del propio partido. El Parlamento aprobará o desechará los proyectos de ley de acuerdo con la voluntad del primer ministro, p. 118. 
En estos momentos ya quisiera el señor Clinton poseer el diez por ciento del control efectivo que el señor Blair tiene respecto al Poder Legislativo de su país.

Por el contrario, si en el sistema parlamentario existen múltiples partidos y para poder formar gobierno es indispensable la conformación de coaliciones que no resultan estables, entonces surgirá un gabinete tras del otro, creándose una inestabilidad política que repercute negativamente en el país, como aconteció en la Francia de la IV República y en Italia a partir de la segunda guerra mundial. Así, la preocupación en esos países fue la de introducir en sus sistemas elementos del régimen presidencial con la finalidad de otorgarles estabilidad.

D. Lo mismo que he afirmado de los regímenes presidenciales y de los parlamentarios respecto al sistema de partidos, es válido en lo referente al llamado régimen semi presidencial cuyo ejemplo clásico en la actualidad es la Constitución francesa de la V República de 1958, ${ }^{9}$ que ha funcionado bien en la realidad y en las circunstancias políticas de ese gran país, pero esa Constitución en ocasiones funciona casi como un sistema presidencial y en otras ocasiones casi como un sistema parlamentario. ${ }^{10}$ Probablemente fuera más acertado suprimir el "casi”.

9 Véase Ardant, Philippe, Institutions politiques et droit constitutionnel, París, LGDJ, 1996, pp. 432-519. Planas, Pedro, Regímenes políticos contemporáneos, México, Fondo de Cultura Económica, 1997, pp. 293-320. Prélot, Marcel y Boulouis, Jean, Institutions politiques et droit constitutionnel, París, Dalloz, 1980, pp. 663-721, 805-810 y 845-856. Hauriou, André, Derecho constitucional e instituciones políticas, Barcelona, Ariel, 1971, pp. 532-609.

10 Sartori, Giovanni, Ingeniería constitucional comparada, México, Fondo de Cultura Económica, 1994, pp. 148-149, realiza una caracterización de los sistemas semi presidenciales. Lijphart, Arend ("Presidencialismo y democracia mayoritaria: observaciones teóricas", en Linz, Juan J. y Valenzuela, Arturo (comps.), Las crisis del presidencialismo. I. Perspectivas comparativas, Madrid, Alianza Universidad, 1997, pp. 153-154) cita a diversos autores que concluyen que el sistema semipresidencial en la realidad es una alternancia de sistema presidencial y sistema parlamentario pero no es un sistema mixto o híbrido: "Raymond Aron escribió en 1981: 'El presidente de la República es la autoridad suprema (es decir, el auténtico jefe de gobierno) en tanto que tenga una mayoría en la Asamblea Nacional; pero debe ceder la realidad del poder al primer ministro en el caso de que un partido que no sea el suyo tenga la mayoría en la Asamblea'. Esto es exactamente lo que sucedió en 1986: el primer ministro Jacques Chirac se convirtió en el jefe de gobierno y el presidente François Mitterrand se vio reducido a un mero papel especial en política exterior. Los sistemas finlandés y portugués ... después de 1982 recuerdan al modelo francés en 1986-1988, y por tanto deberían clasificarse como parlamentarios. Es posible que pueda diseñarse un sistema auténticamente medio presidencial y medio parlamentario — quizá especificando en la Constitución que el presidente y el primer ministro encabecen conjuntamente el gobierno-, pero en la realidad no hay ejemplos de estos regímenes intermedios. En concreto, la Quinta República es generalmente presidencial en lugar de semi presidencial, y sólo ocasionalmente parlamentaria. Maurice Duverger, 
Funciona casi como un sistema presidencial cuando el partido político o partidos afines del presidente de la República cuenta o cuentan con la mayoría de legisladores en la Asamblea Nacional, porque entonces él designa con libertad al primer ministro, quien es de su propio partido y quien le reconoce jerarquía política. Es el presidente quien encabeza el gabinete y quien toma las decisiones más importantes del gobierno.

Pero la misma Constitución francesa de 1958 funciona como un sistema casi parlamentario, cuando el partido político y los afines al presidente de la República no cuenta o cuentan con la mayoría de los legisladores en la Asamblea Nacional o no puede configurar una coalición, entonces el presidente tendrá que designar como primer ministro al líder del partido que tiene esa mayoría o al líder que pueda formar un gobierno $\mathrm{y}$ en este caso es el primer ministro quien gobierna. El presidente, ciertamente, tiene sus facultades enumeradas (reservadas) en la Constitución, pero entonces muchas de ellas se vuelven más virtuales que reales porque quien formula y controla el presupuesto es el jefe del gobierno (el primer ministro) y no el presidente, y si este último no cuenta con recursos económicos para ejercer sus facultades, entonces su papel se parece al de un jefe de Estado en un sistema parlamentario. Desde luego no puede desconocerse que la personalidad del presidente de la República es un factor que influye en todo este esquema.

\section{EL PRINCIPIO DE NO-REELECCIÓN}

Un aspecto que los mexicanos debemos tener muy en cuenta es que en un sistema parlamentario, el primer ministro puede reelegirse cuantas veces gane su partido las elecciones. En las últimas décadas hemos visto la reelección reiterada de varios primeros ministros o sus equivalentes, sólo por mencionar a algunos recordemos a Felipe González, Margaret Thatcher y Helmut Kohl.

anticipando acertadamente el paso a parlamentarismo en 1986 y de nuevo a presidencialismo en 1988 - tan presciente como Aron-, concluye que la Quinta República no es 'una síntesis de los sistemas parlamentario y presidencial', sino una 'alternancia' entre fases presidenciales y parlamentarias". Del llamado sistema semi presidencial — que no es tal— vale la pena examinar la Constitución alemana de 1919 y la española de 1931, y más recientemente la portuguesa de 1982. 
En México, parte esencial de nuestra historia y experiencia constitucionales, está representada por el principio de no reelección del presidente de la República, principio que ha sido y es un factor muy positivo de nuestro sistema político. Este aspecto debe ser meditado y remeditado.

Los mexicanos no podemos olvidarnos que cuando un presidente llegaba al poder, se perpetuaba en él y sólo se le podía sustituir por la fuerza de las armas o por su muerte; tal fue la situación con Santa Anna, Juárez, Lerdo de Tejada y Porfirio Díaz. Entre ellos cuatro gobernaron 58 de los primeros 90 años del México independiente.

Tampoco podemos olvidarnos que la llamada Revolución Mexicana tuvo como lema político el principio de "sufragio efectivo, no reelección", que la Constitución de 1917 hizo de esta máxima, precepto esencial del nuevo orden constitucional, pero que dicho principio se desmoronó cuando la fuerza personal del caudillo logró que se reformara dos veces nuestra ley fundamental para permitir la reelección del general Álvaro Obregón, quien después de las elecciones y antes de ser declarado presidente constitucional, fue asesinado, lo que salvó a México de contar con un segundo Porfirio Díaz, pues difícilmente se hubiera podido sacar a Obregón de la silla presidencial, ya que también hubiéramos tenido en este siglo nuestro 1890; o sea, la reforma constitucional que permitiría la reelección del presidente de la República sin ningún límite.

La muerte de Obregón hizo posible que el 29 de abril de 1933 apareciera publicada en el Diario Oficial de la Federación una nueva reforma al artículo 83 constitucional para, otra vez, prohibir la reelección del presidente de la República, reforma que es la que subsiste hasta nuestros días. ${ }^{11}$

Todos sabemos que la mayoría de los presidentes mexicanos han sido muy fuertes, especialmente a partir del general Lázaro Cárdenas, pero desde 1933 ninguno de ellos intentó realmente reelegirse a pesar de múltiples rumores al respecto. ${ }^{12}$ El principio de no reelección presidencial es base y corazón de nuestro orden constitucional. Es nuestra evolución y resultado de experiencias políticas que están presentes y nos concitan a

11 Carpizo, Jorge, El presidencialismo..., cit., pp. 55-58.

12 Véase Goodspeed, Stephen Spencer, "El papel del jefe del Ejecutivo en México", Problemas agrícolas e industriales de México, México, Talleres Gráficos de la Nación, 1955, vol. VII, p. 155. Cosío Villegas, Daniel, La sucesión presidencial, México, Joaquín Mortiz, 1975, pp. 113, 118-120. Lerner de Sheinbaum, Bertha y Ralsky de Cimet, Susana, El poder de los presidentes. Alcances y perpectivas (1910-1973), México, Instituto Mexicano de Estudios Políticos, 1976, pp. 246-248. 
no cometer un error político garrafal: olvidarnos de las crisis y el fenomenal costo político que hemos pagado cuando nuestros presidentes han podido reelegirse.

Se podría argumentar que México ha cambiado mucho desde 1917 y 1933 y que la democracia implica que el pueblo pueda reelegir a su presidente cuantas veces quiera. A este punto específico me refiero más adelante. Ahora sólo diré que hay naturalezas humanas - y son innumerables - que aman el poder y cuando lo detentan no lo quieren abandonar, se les vuelve una especie de droga que los invade y los domina. La historia universal habla por ella misma y la mexicana también.

En los últimos años en América Latina hemos visto asombrados cómo los presidentes Fujimori del Perú, Menen de Argentina y Cardoso del Brasil lograron - porque tuvieron la fuerza política para ello- reformas constitucionales para su reelección, la cual obtuvieron, y cómo después de esos periodos presidenciales, los dos primeros mencionados intentaron con todas sus fuerzas obtener otro periodo presidencial. En este momento Menen ya no lo alcanzó ante el rechazo popular y Fujimori se encuentra aún intentándolo ¿lo logrará?

Entonces, a los partidarios de un sistema parlamentario en México hay que recordarles nuestra historia política y decirles: mucho ojo, cuidado, mucho ojo, ;reflexionen!

No está de más también traer a colación la máxima atribuida a Lord Acton: el poder corrompe y el poder absoluto corrompe absolutamente. El poder necesita pesos y contrapesos; necesita límites y, sin ninguna duda, en México el límite del tiempo es un imperativo histórico que nuestra evolución ha convertido en un imperativo político.

Ha llegado el momento de introducirme al mundo de las ideas y de las teorías, el cual es muy importante porque auxilia a quienes, por mandato electoral, toman las decisiones políticas, especialmente en temas tan importantes, delicados y de múltiples aristas como es todo lo concerniente al sistema de gobierno en un país.

\section{LA DISCUSIÓN DOCTRINAL}

En los últimos años se ha dado una importante y muy interesante discusión doctrinal sobre las ventajas y los inconvenientes de los sistemas parlamentarios y presidenciales. De ella han surgido propuestas de cam- 
bios especialmente para los países latinoamericanos y los poscomunistas de la Europa oriental.

Esta discusión se originó por diversos estudios — primordialmente de los profesores Riggs y Linz- de carácter estadístico en los cuales resaltan que, durante los años sesenta y setenta, mientras diversas democracias de sistema presidencial fracasaron, las de sistema parlamentario mantuvieron su estabilidad. En consecuencia, cabría la suposición de que el sistema de gobierno algo tiene que ver con la estabilidad o la inestabilidad del propio gobierno y con el posterior descalabro de esa democracia. Entonces, las proposiciones doctrinales para superar dicho "problema" no se hicieron esperar.

Sartori escribió que respecto a las cuestiones institucionales la pregunta esencial es: ¿sabemos qué reformar y cómo lo vamos a hacer? $\mathrm{Su}$ preocupación estriba en dilucidar si conocemos qué es lo que debe cambiarse y cómo cambiarlo, y contesta que no, lo cual ha tenido como consecuencia que "las reformas realizadas llevan la huella de reformadores muy incompetentes". 13

Reformar por reformar sin una profunda reflexión, sin conocimiento amplio de la realidad jurídica, política, social y económica de una comunidad, constituye un verdadero desaguizado, porque para los cambios político-jurídicos no existen "recetas", sino que los instrumentos del derecho y de la política comparados nos otorgan ideas, nos sugieren caminos que debemos meditar para ponderar cuáles de ellos pudieran ser útiles a la realidad concreta de un determinado país. Copiar instituciones exitosas de una nación a otra sin considerar la realidad de la receptora, generalmente conducen a un fracaso estrepitoso que lo único que logran es magnificar los problemas que se querían resolver con esa "receta". Analizar los fracasos de sistemas e instituciones políticas son de provecho si estudiamos las causas de ese malogro y el porqué no funcionaron en la realidad de ese país.

En este aspecto es elocuente, verdadera y precisa la expresión de Charles de Gaulle que escogí como epígrafe para este ensayo.

Veamos las ideas de algunos tratadistas que han intervenido en este debate y que en mi opinión merecen examinarse. 


\section{LA TESIS DE JUAN LINZ}

A. Un punto de referencia esencial en este debate son los estudios del muy distinguido politólogo Juan Linz, quien es un gran defensor y promotor de las ventajas del sistema parlamentario sobre el presidencial. Linz profundiza en aspectos poco estudiados de los sistemas de gobierno y aunque no se esté de acuerdo con él, hay que reconocer los indudables méritos de sus análisis.

Linz parte del principio de que puede ser o no una casualidad que muchos sistemas presidenciales han encontrado serios problemas para establecer democracias estables. Después de examinar ambos sistemas de gobierno y de exponer sus argumentos en favor del sistema parlamentario, aclara que una democracia presidencial sí puede ser un sistema estable aunque sus probabilidades en este sentido no son realmente favorables. Asimismo, expresa que los sistemas parlamentarios no siempre garantizan la estabilidad sino que facilitan la flexibilidad indispensable en los difíciles pasos hacia la transición democrática.

Linz aclara su pensamiento al asentar: "Sólo insisto en que el presidencialismo parece que supone un mayor riesgo para una política democrática estable que el parlamentarismo contemporáneo". ${ }^{14}$

Resalta la prudencia de este tratadista respecto a sus afirmaciones, con lo cual prueba su talento y él mismo acepta que para llegar a conclusiones definitivas aún faltan estudios empíricos. Lo importante es que el examen de los sistemas de gobierno — que estaba muy descuidado-, ha adquirido especial presencia a partir de estudios serios como los de Juan Linz y los de Arturo Valenzuela, que invitan a la meditación y al debate.

B. Los principales argumentos de Linz, en síntesis, para sostener su tesis, son los siguientes:

a) En el sistema presidencial hay una legitimidad democrática dual al ser el presidente electo directamente. Legitimidad democrática de la cual también gozan los legisladores y cuando la mayoría de ellos representa una opción política distinta a la de aquél, puede darse un conflicto entre poderes que los recursos procesales-constitucionales difícilmente resolverán y que incluso puede llevar a la intervención del ejército como "poder moderador".

14 Linz, Juan J., “Democracia presidencial o parlamentaria: ¿qué diferencia implica?”, Las crisis del presidencialismo. I. Perspectivas comparativas, cit., pp. 28, 124 y 137. 
b) En el sistema presidencial, el Ejecutivo es electo para un periodo fijo, sin que exista la posibilidad de introducir ajustes según lo requieran los sucesos políticos, económicos y sociales. En el sistema parlamentario ante dichos sucesos el primer ministro puede solicitar un voto de confianza al Poder Legislativo y si lo logra se fortalece su autoridad y legitimidad democrática; pero si no lo consigue, acontecerá un cambio de gobierno, lo cual otorga flexibilidad a ese sistema. En estos casos es generalmente el pueblo a través de la nueva elección, el que decide cuál de los poderes tenía la razón,

c) En el sistema presidencial se efectúa un juego de "gánalo todo", ya que el candidato victorioso, él solo integra el Poder Ejecutivo, mientras que en el sistema parlamentario un primer ministro que no alcanza más del $50 \%$ de los escaños, está compelido a formar un gobierno de coalición o a tener un gobierno minoritario mientras éste pueda subsistir.

El propio Linz acepta que en un sistema parlamentario como el inglés, cuando un partido alcanza cuando menos la mayoría de los escaños en la cámara baja "se produce una situación de gánalo todo", lo que no acontece en un sistema presidencial si el Ejecutivo triunfador no cuenta con mayoría en una o en las dos cámaras del Congreso.

Este tratadista precisa que:

El carácter de suma cero que el juego político tiene en los regímenes presidenciales se ve reforzado por el hecho que los ganadores y perdedores están definidos por el periodo del mandato presidencial, una serie de años durante los cuales no hay esperanza de modificar las alianzas, de ampliar la base de apoyo gracias a grandes coaliciones de unidad nacional o de emergencia, de disolución y nuevas elecciones, en situaciones de crisis, etcétera. Los perdedores tienen que esperar cuatro o cinco años, sin acceso al Poder Ejecutivo y por tanto a la posibilidad de intervenir en la formación de los gobiernos, y sin acceso a la oportunidad de repartir toda suerte de ventajas y puestos entre sus correligionarios. El juego de suma cero aumenta los embates en una elección presidencial tanto para los ganadores como para los perdedores e inevitablemente aumenta la tensión y la polarización. ${ }^{15}$

d) En el sistema presidencial, la responsabilidad y la obligación de rendir cuentas de la estabilidad y de la política de gobierno corresponden únicamente al Poder Ejecutivo. Por ello es "muy probable" que los par-

15 Linz, Juan J., op. cit., pp. 33, 34, 37, 38, 46, 47, 54 y 55. 
tidos políticos de oposición se opongan, critiquen e incluso fiscalicen al presidente, sin otorgarle ningún apoyo ni responder a sus iniciativas, menos a responsabilizarse de ellas.

Si los partidos, incluido el del propio presidente, apoyan medidas impopulares de éste, no tendrán ninguna recompensa por ello. En cambio, sí pueden verse electoralmente castigados. Esta es la razón por la cual un presidente se ve obligado a usar medidas clientelísticas y al reparto de beneficios para intentar neutralizar a la oposición.

Para Alonso Lujambio, desde la perspectiva de Linz, éste es uno de los aspectos de mayor potencial de conflicto entre el Ejecutivo y el Legislativo, y el que puede causar la parálisis del propio sistema de gobierno, sin que existan los medios flexibles que otorga el sistema parlamentario para superar esa parálisis como son la disolución de la legislatura por el Ejecutivo o la moción de censura al primer ministro. ${ }^{16}$

Linz afirma que el sistema presidencial ha reforzado en algunos países el aspecto no estructurado, la indisciplina y la rigidez ideológica de los partidos políticos. ${ }^{17}$

e) En el sistema presidencial la concentración de poderes en el Ejecutivo ha impulsado en muchas ocasiones a limitar a éste en el tiempo -el principio de no reelección - lo cual resulta "frustrante" para líderes ambiciosos quienes intentan reformar la Constitución para continuar en el poder. A veces - indica Linz- la conciencia de que el tiempo para actuar es limitado tiene un impacto en el estilo de la política y la posible desconfianza al sucesor, lo cual imprime una sensación de urgencia que contribuye al diseño incorrecto de las políticas, a ponerlas en práctica con precipitación, a impacientarse con la oposición, a realizar gastos que deberían distribuirse a través del tiempo y a implantar políticas que pueden auspiciar tensiones y ser ineficaces.

Una persona que ha ocupado la presidencia con tal cúmulo de poderes difícilmente se va a resignar a no volver a ocupar ese cargo y más si su sucesor fracasa. Ello puede propiciar que aquél trate de ejercer el poder

16 Lujambio, Alonso, Federalismo y Congreso en el cambio político de México, México, UNAM, Instituto de Investigaciones Jurídicas, 1995, pp. 14-15. Carrillo, Ulises y Lujambio, Alonso, "La incertidumbre constitucional. Gobierno dividido y aprobación presupuestal en la LVII Legislatura del Congreso mexicano, 1997-2000”, Revista Mexicana de Sociología, México, UNAM, 1998, vol. 60 , núm. 2 , pp. 242-243.

17 Linz, Juan J., op. cit., pp. 126-127. 
detrás del trono o a influir en la sucesión presidencial con un candidato diferente al del titular del poder.

f) En el sistema presidencial se carece de un rey o de un jefe de Estado que pueda intervenir simbólicamente como un poder moderador y que pueda en casos de crisis actuar como un poder neutro que colabore a superarlos.

g) En el sistema presidencial es factible, no así en el parlamentario, que un "extraño" acceda al poder, y más si en ese país no existe un sistema de partidos fuertes. Ese "extraño" puede no tener experiencia gubernativa ni política y puede presentarse, incluso, con hostilidad a los partidos y a los políticos. Estas candidaturas pueden surgir repentinamente y aprovechar el malestar y la frustración sociales, capitalizando la esperanza de que se tiene un "salvador". El problema es que esta clase de presidentes no cuenta con apoyos en el congreso al ser ajeno a un partido político y generalmente no tiene el tiempo suficiente para construir una organización partidista. Únicamente en sistemas presidenciales pueden llegar al poder candidatos como Fujimori, Collor de Mellor o Aristide.

h) En el sistema presidencial, las elecciones revisten aspectos marcadamente individualistas, de carácter plebiscitario; más que por un partido y un programa se vota por una persona a la que se considera la mejor para responsabilizarse del destino del país y a la cual se le deja gobernar la nación con bastante discrecionalidad y hasta donde los límites que las relaciones de poder lo soporten. Dicho carácter plebiscitario, que permite al candidato prometer todo y de todo, muchas veces de manera irresponsable, otorga a los presidentes después de la elección un índice de aprobación muy alto que puede llegar a 70 u 80 por ciento, lo cual raramente acontece en un sistema parlamentario.

Linz cita a O'Donnell, quien afirmó que a los presidentes, "hoy se les aclama como figuras providenciales, mañana se les maldice como a dioses caídos".

Sin embargo, el propio tratadista admite que incluso en los sistemas parlamentarios, cada vez con mayor frecuencia, se vota por el líder del partido que se piensa puede gobernar mejor. Es decir, la personalización del liderazgo es actualmente una realidad también en dichos sistemas.

i) En el sistema presidencial, el hecho de que en muchos casos existe un vicepresidente quien remplazará automáticamente al presidente en ca- 
sos como fallecimiento, incapacidad o destitución, puede presentar problemas porque: se dan conflictos entre ellos, a veces el vicepresidente es electo en forma separada al presidente, el vicepresidente puede representar una opción o a un partido diferente al del presidente, o este último lo escogió como compañero de fórmula para la elección, no por sus cualidades para gobernar, sino para que le ayudara a ganar la elección plebiscitaria. ${ }^{18}$

C. Claro está que después de esta crítica demoledora al sistema presidencial, Linz es partidario del parlamentario porque su "presunción" es que este sistema propicia: a) mayor responsabilidad hacia el gobierno por parte de los partidos y de sus líderes; b) mayor obligación a los propios partidos de rendir cuentas — salvo en un fraccionamiento político extremo-; c) la necesidad de los partidos de cooperar y de realizar compromisos - a menos que uno de ellos gane la mayoría absoluta de las curules-; d) que en caso necesario de un cambio en el liderazgo, éste se efectúe sin una crisis de régimen; y, e) una continuidad en el gobierno sin el miedo del continuismo como ocurre en los sistemas presidenciales.

Linz realiza un buen estudio de los sistemas mixtos — semi parlamentario y semi presidencial - y está decididamente en contra de ellos. Sin embargo, dice que en América Latina, estos sistemas mixtos constituyen una manera indirecta y "subrepticia" de inclinarse por el sistema parlamentario, para incorporar prácticas parlamentarias pero conservando los símbolos del presidencialismo. Esta actitud la atribuye a la falta de disposición y voluntad para atreverse a realizar un cambio radical en la evolución político-constitucional. Este autor manifiesta $-\mathrm{y}$ aquí le asiste toda la razón - que el sistema parlamentario no goza del favor de los políticos ni de los constitucionalistas en América Latina. ${ }^{19}$

D. Este distinguido autor ejemplifica sus aseveraciones con diversos y abundantes casos referentes a América Latina. Llama la atención que no se refiera a México, salvo respecto al principio de no reelección. ¿Por qué? Como no lo dice, se puede especular: ¿Porque no considera que México es un régimen democrático? ¿Porque ha tenido estabilidad política por décadas aunque el sistema real que ha conocido es una degeneración del presidencial? ¿Porque un sistema que fue políticamente no competitivo, no le era útil para su análisis? 


\section{LAS CRÍTICAS A LA TESIS DE JUAN LINZ}

La tesis y argumentos de Juan Linz han recibido diversas críticas y yo agrego otras, pero hay que ser claros de que el propio Linz se ha dado cuenta de que varios de sus argumentos se pueden controvertir y él se ha adelantado a varias de las objeciones y ha contrargumentado.

Las principales críticas que se pueden hacer a la tesis de Linz son las siguientes:

a) Varios sistemas presidenciales en América Latina ciertamente han sido inestables, mientras que en Europa los sistemas parlamentarios, en lo general, han sido estables especialmente a partir de la segunda guerra mundial aunque hay excepciones.

Atribuir inestabilidad o estabilidad a una democracia únicamente por el sistema de gobierno sin referirse a otros factores, no es correcto porque en América Latina la inestabilidad política de las democracias responde primordialmente a problemas graves como la profunda desigualdad social, la pobreza, la falta de educación en grupos numerosos, el retraso económico, la no integración de grupos étnicos, la explosión demográfica, la falta de cultura cívica, rezagos sociales inmensos y, a veces, a la existencia de partidos políticos débiles.

b) A pesar de todos los problemas arriba señalados, en América Latina hay y han habido sistemas presidenciales democráticos que gozan y han gozado de estabilidad y Linz no se refiere a ellos o sólo muy de pasada: por ejemplo, Costa Rica desde 1948, Venezuela desde 1958, Chile entre los años treinta a 1973 y Uruguay entre los años cuarenta a 1973. Es decir, en estos casos, esas democracias presidenciales han funcionado o funcionaron por más de 25 años, o sea en ellas existieron elementos estabilizadores. ${ }^{20}$

c) Comparar en América Latina el sistema presidencial —que sí existe - con el sistema parlamentario - que no se le conoce y en el pasado sólo existió por breves periodos y con inestabilidad - resulta una especulación muy favorable al parlamentarismo porque cuando éste existió fue un "sistema trunco" y nada exitoso desde la perspectiva de la estabilidad. $^{21}$

20 Ibidem, p. 66.

21 Nohlen, Dieter, "Sistemas de gobierno: perspectivas conceptuales y comparativas", en Nohlen, Dieter y Fernández, Mario (eds.), Presidencialismo versus parlamentarismo. América Latina, 
d) En América Latina a partir de 1978, lo cual ya es parte de su historia, muchas transiciones democráticas tuvieron como cauce el sistema presidencial y muchas de ellas "con el mismo marco constitucional vigente en la época del desplome preautoritario". Desde luego que la consolidación democrática y su éxito está relacionado con la eficiencia del gobierno. ${ }^{22}$

e) La elección del presidente para un periodo fijo y rígido otorga estabilidad al régimen porque el congreso no podrá interrumpir ese periodo con una moción de censura. El gobierno conoce que cuenta con un tiempo determinado - generalmente no acortable — para desarrollar el programa que propuso durante la campaña electoral.

f) En los sistemas presidenciales no se da un juego de "gánalo todo", tal y como lo expresó este autor, quien admitió que cuando el partido del presidente es minoritario en el congreso, este principio se modifica radicalmente.

Alonso Lujambio en este aspecto manifiesta que el sistema federal constituye un importante elemento para "aminorar el carácter mayoritario y excluyente de la democracia presidencial", ya que los partidos derrotados a nivel nacional, pueden ganar gubernaturas, diputaciones locales y municipios, con lo que reducen su resentimiento y frustración ante la derrota por la presidencia y se debilita su posible actitud antisistema ya que están gobernando en lugar de sólo oponerse; al gobernar se sensibilizan de la complejidad de los problemas sociales y de las funciones de gobierno, lo cual trae consigo un asentamiento o conciliación entre las élites, que es muy importante para la estabilidad de un régimen democrático.

Caracas, Editorial Nueva Sociedad, 1991, pp. 20-22. Este autor sostiene que respecto al sistema parlamentario en América Latina se deben destacar tres problemas: "En primer lugar, las pocas experiencias son negativas. En Chile, el periodo 1891-1925 se denomina 'parlamentario' aunque de esa forma sólo tenía la capacidad del parlamento para censurar ministros (no así al jefe de gobierno, característica clave de un sistema parlamentario), y el juicio predominante sobre el periodo es haber producido una gran inestabilidad para gobernar y una oligarquización de la política. En segundo lugar, las posiciones favorables a la aplicación de un sistema parlamentario actualmente son minoritarias, así como las condiciones político institucionales para lograrlo. Así lo demuestran los debates en varios países en América Latina en los últimos años y se evidencia en este mismo libro, con la única excepción de Brasil. En tercer lugar, varias Constituciones latinoamericanas contienen elementos parlamentarios, pero en la práctica no han podido establecerse. Es raro en América Latina el caso de un presidencialismo puro".

22 Ibidem, p. 24. 
Además, los partidos de oposición al gobierno federal al ganar elecciones locales tienen la oportunidad de demostrar que son opciones políticas serias y responsables que sí saben cómo gobernar. ${ }^{23}$

g) El mismo Alonso Lujambio y Ulises Carrillo expresan que los partidos de oposición al del presidente en el congreso sí pueden cooperar con aquél porque no todos los partidos políticos en los sistemas presidenciales tienen la ambición de alcanzar ese cargo en el corto y mediano plazo, porque son demasiado pequeños para ello aunque, desde luego, si el sistema de partidos tiene una fragmentación moderada, los partidos que aspiran a la presidencia son más numerosos que si la fragmentación es extrema.

Estrategias de crecimiento o sobrevivencia partidista pueden encontrar rentable un comportamiento cooperativo, dependiendo de la situación política y de la forma en la cual el presidente y su partido son percibidos por el electorado. En cualquier caso, nuestro argumento intenta entrelazar todas estas variables: en un sistema de partidos de fragmentación moderada, los partidos de oposición no desean cooperar debido a que priorizan en su estrategia de corto plazo la probabilidad de una victoria próxima de la competencia presidencial, pero, al mismo tiempo, pueden pagar el costo de una parálisis institucional derivada de actitudes claramente identificadas como no cooperativas o, aún peor, obstruccionistas. $^{24}$

Estos autores concluyen en forma preliminar que el argumento de Linz tiene fuerza en sistemas de fragmentación moderada en donde los partidos con ambición presidencial sienten como electoralmente costosa la cooperación con el presidente.

Empero, lo mismo se puede afirmar que acontece en un sistema parlamentario si el primer ministro no cuenta con mayoría de legisladores en la cámara baja y el partido o partidos que integran la coalición perciben que apoyar determinado proyecto del primer ministro les va a significar un elevado costo electoral y ni qué decir de los partidos de oposición. En un sistema parlamentario con esa correlación de partidos, una iniciativa así puede incluso traer consigo la caída del propio gobierno.

h) El principio de no reelección, que no lo tienen todos los sistemas presidenciales y que adquiere diversos matices de acuerdo con el régi-

23 Lujambio, Alonso, op. cit., pp. 23, 24, 51, 52 y 99.

24 Carrillo, Ulises y Lujambio, Alonso, op. cit., pp. 243-244. 
men, puede ser una de sus causas de estabilidad política como en el caso de México, al cual ya me referí.

La alternancia en el poder decidida por el pueblo es un elemento característico de la democracia. Al más alto nivel político es la evolución constitucional de cada Estado la que determina cuál es la norma más adecuada para ese país en este aspecto. En este caso, como en tantos otros, las "recetas" fracasan y se estrellan ante la obstinada realidad.

La mejor prueba de las anteriores afirmaciones nos la presentan los Estados Unidos de Norteamérica, donde Washington al no haber aceptado reelegirse para un tercer periodo, estableció una costumbre constitucional que se respetó hasta que Franklin D. Roosevelt - un gran presidente, uno de los mejores de su país - logró reelegirse para un cuarto periodo. La reacción subsiguiente fue la reforma de la Constitución de ese país, a través de la enmienda 22, para limitar a dos los periodos del presidente norteamericano, de cuatro años cada uno. ${ }^{25}$

En varias épocas se ha sugerido en ese país que el presidente sólo debe ocupar el cargo durante un único periodo de cuatro, seis o siete años: en este sentido se pronunciaron los presidentes Andrew Jackson, Andrew Johnson, Hayes y Taft, asimismo Lyndon Johnson y Nixon no vieron con desagrado tal posibilidad. ${ }^{26}$

i) No todos los sistemas presidenciales cuentan con una vicepresidencia. Este aspecto no constituye una nota esencial del sistema. Lo importante es que ante la falta del presidente, exista un mecanismo rápido de sustitución que impida la inexistencia del Poder Ejecutivo central o federal. Por ejemplo, la historia constitucional de México demuestra que la vicepresidencia ha sido nefasta en nuestro país, por lo que se creó en 1917 un sistema a través del cual no se conoce de antemano quién sustituye al presidente si éste llega a faltar. Las veces que dicho mecanismo ha tenido que ser aplicado, lo ha sido con agilidad y suavidad. En otras palabras, ha operado bien. ${ }^{27}$

j) No hay ninguna evidencia empírica para sostener que en comunidades social y económicamente inestables y que políticamente han sido

25 Carpizo, Jorge, El presidencialismo..., cit., pp. 59-60.

26 Schlesinger, Jr. Arthur M., The imperial presidency, Boston, Houghton Mifflin, 1973, pp. 386-387; Taft, William Howard, The president and his powers, Nueva York, Columbia University Press, 1967, p. 4; Corwin, Edward S., El Poder Ejecutivo. Función y poderes. 1787-1957, Buenos Aires, Ed. Bibliográfica Argentina, 1959, p. 39.

27 Carpizo, Jorge, El presidencialismo..., cit., pp. 63-68. 
hasta hace poco refundadas en el método democrático, el sistema parlamentario auxiliará a que la consolidación democrática se fortalezca y sea realmente sólida. Todo lo contrario, existe profunda preocupación por un cambio de sistema de gobierno que pueda traer consigo constantes renovaciones de gobierno debido a la existencia de varios o múltiples partidos con cierta ideologización y polarización. ${ }^{28}$

\section{LA FÓRMULA DE GIOVANNI SARTORI}

A. Giovanni Sartori parte de la premisa que los sistemas presidenciales funcionan mal y han resultado muy frágiles - salvo, claro está, el de los Estados Unidos de Norteamérica- porque han perecido ante golpes de Estado y otras "calamidades", y ellos no pueden manejar las crisis importantes.

El distinguido profesor de la Universidad de Columbia no está de acuerdo con la tesis de Juan Linz porque — afirma — la democracia parlamentaria no funciona si no existen partidos adaptados al parlamentarismo; es decir, partidos cohesivos y/o disciplinados. Los partidos disciplinados constituyen una condición necesaria para que el sistema parlamentario pueda realmente funcionar porque con partidos indisciplinados dicho sistema cae en la perversión del régimen de asambleas que siempre termina en el fracaso.

Por ello, una posibilidad es la sustitución del sistema presidencial por uno semi presidencial; como el modelo francés, que otorga al sistema la flexibilidad que al primero le falta, aunque este último deja muchos problemas sin resolver y es algo frágil.

Empero, Sartori tiene una propuesta que considera mejor que el sistema arriba mencionado, que aconseja para América Latina y específicamente para México: el presidencialismo alternativo o presidencialismo intermitente. Este destacado autor señala que tanto el sistema presidencial como el parlamentario es impulsado por un motor. En uno, es el presidente y en el otro, el parlamento. El sistema semi presidencial tiene dos motores que marchan en forma simultánea y conlleva el peligro de que vayan en direcciones opuestas e incluso que pueden llegar a estar el uno contra el otro

28 Nohlen, Dieter, op. cit., p. 33. 
Su propuesta reside en un sistema con dos motores que no se encienden simultánea sino probablemente en forma sucesiva. Los dos motores son electos al mismo tiempo y por el mismo periodo. El sistema comienza operando como parlamentario y, si funciona bien, continúa como tal, pero si no, se apaga el motor parlamentario y se prende el presidencial y entonces se reviste de las características propias de este último. En esta forma durante el periodo parlamentario, lo esencial es tener "una zanahoria que recompense el buen desempeño y un garrote que sancione la mala conducta" ${ }^{29}$

Sartori precisa que su fórmula descansa fundamentalmente en tres acuerdos estructurales: a) el parlamento que se acaba de constituir, elige un gobierno "si la legislatura dura cuatro años, y dos si dura cinco años", lo cual implica que ese sistema funcionará de acuerdo con las reglas del sistema parlamentario normal, b) si ese gobierno parlamentario fracasa, entonces se cambia a uno presidencial "fuerte" por el resto del periodo de la legislatura; o sea, el presidente se convierte también en jefe de gobierno al cual no se le puede dar un voto de censura pero él no puede disolver el parlamento, c) el periodo del presidente, quien es electo directa o indirectamente por el sufragio de una mayoría absoluta del voto popular — si es necesario a través de una segunda vuelta - y el periodo del Poder Legislativo coinciden. El presidente puede ser reelecto sin ninguna limitación.

Giovanni Sartori completa su fórmula con otras consideraciones: d) mientras transcurre el periodo parlamentario, el presidente es un presidente parlamentario normal cuyas funciones son las que corresponden a un jefe de Estado parlamentario, en principio sin ninguna de carácter gubernativo, e) el presidente tiene una legitimidad "reservada" y si el sistema parlamentario funciona bien, no será necesaria la alternancia al sistema presidencial porque es inútil utilizar el garrote contra el parlamento, f) el gobierno parlamentario será "más efectivo y emprendedor" con el fin de conservar la zanahoria y gobernar realmente durante todo el periodo, g) los cargos parlamentarios y los ministeriales son incompatibles entre sí, para que el presidente no se vaya a ver tentado a compensar a los legisladores que lo hayan ayudado a prender el motor presidencialista, h) el presidente intermitente termina su periodo al mismo tiempo que la legislatura, y no puede convertirse en un presidente presidencialista al principio de cada legislatura, i) si se prende el segundo

29 Sartori, Giovanni, op. cit., pp. 101, 111, 112, 155 у 168. 
motor por el fracaso del parlamento, entonces es un presidente fuerte pero es probable que su poder real sea sólo de dos a tres años.

El autor de Ingeniería constitucional comparada, concluye y se cuestiona, en síntesis, si su propuesta del sistema presidencial alternativo o intermitente "¿Es difícil entenderlo y llevarlo a la práctica? De ninguna manera. La idea básica es — dice- que a un sistema parlamentario que funciona se le recompensa permitiéndole continuar, en tanto que a un sistema parlamentario que no funciona, se le sanciona descontinuándolo. Sin duda ésta es una idea fácilmente comprensible", ${ }^{30}$ y todo lo que se necesitará será una reforma constitucional para introducir los mecanismos parlamentarios en ese sistema de gobierno, a lo cual Sartori no le encuentra dificultades.

B. La propuesta de Sartori constituye un buen ejercicio intelectual; sin embargo, es muy dudoso que en la práctica pueda tener buenos resultados. Diego Valadés le ha hecho las siguientes críticas:

a) el parlamento estaría dispuesto a tolerar un gobierno débil ante la perspectiva de tener que enfrentarse a un presidente fuerte,

b) ese gobierno débil estaría interesado en negociar continuamente posiciones políticas con el parlamento para permanecer como tal e incluso para no ser posteriormente acosado por el presidente,

c) el presidente, ante la posibilidad de tomar realmente el poder, sería cortejado por miembros del congreso o del gobierno, lo que le daría una fuerte influencia desequilibradora,

d) el arribo del sistema presidencial como consecuencia del fracaso del parlamentario, acentuaría las características autoritarias del presidencialismo,

e) habrían fuerzas políticas interesadas en el fracaso del sistema parlamentario para legitimar el endurecimiento político,

f) para superar el fracaso del sistema parlamentario se enciende el motor del presidencial, pero en el siguiente periodo se comienza de nuevo con el sistema parlamentario que ha tenido hace poco tiempo considerables tropiezos: ¿cómo explicar esta contradicción?,

g) en lugar de conseguir alternativamente las ventajas del sistema parlamentario y del presidencial, lo que se lograría sería la alternancia de sus defectos: debilidad y dureza. ${ }^{31}$

30 Ibidem, pp. 170-175.

31 Valadés, Diego, El control del poder, México, UNAM, Instituto de Investigaciones Jurídicas, 1998, pp. 408-409. 
Además, agregaría otras críticas:

h) el parlamento lucharía por continuar con el sistema parlamentario y el presidente por la instauración del sistema presidencial. Se podría dar un enfrentamiento fuerte entre los poderes y ¿quién decide si el sistema parlamentario ha fracasado o no? Este enfrentamiento podría conducir a una crisis política sin la existencia de instrumentos para resolverla,

i) el presidente tiene una legitimidad democrática idéntica a la del parlamento ya que ambos han sido electos, directa o indirectamente, por el pueblo. ¿Será posible entonces que el presidente se resigne a jugar el papel de jefe de Estado parlamentario sin poderes reales, a tener una simple expectativa de asumir el poder? ¿No hará todo lo que pueda políticamente para que el gobierno parlamentario fracase y él pueda asumir los poderes plenos del gobierno? La propuesta de Sartori invita a la confrontación y a la lucha abierta entre los poderes Ejecutivo y Legislativo: ¿será posible que el parlamento colabore con quien arriba al poder sobre las cenizas del gobierno que él había designado?,

j) el propio Sartori expresa que es necesario al sistema parlamentario la existencia de partidos disciplinados, característica que generalmente es la contraria en los sistemas presidenciales. ¿Será posible que dicha disciplina se la puedan imponer o quitar los partidos como una camiseta dependiendo de si el sistema funciona en ese momento como un sistema presidencial o como uno parlamentario?

C. Los argumentos anteriores me llevan a concluir que esta proposición no corrige los peligros que desea vencer sino que los agrava: el enfrentamiento de los poderes, la profundización de las crisis políticas y la inestabilidad gubernativa.

Por las razones anteriores, la proposición del distinguido profesor Sartori no es una vía para México; sería necesario para que pudiera funcionar que los políticos fueran ángeles y no personas que persiguen el poder para ejercerlo con diversos objetivos y finalidades pero, en todo caso, ejercerlo. Generalmente no han dado resultados los sistemas en los cuales de antemano se conoce quién va a sustituir al titular del poder si éste falta o fracasa porque al sustituto le entra la prisa y la urgencia por ocupar ese lugar. 


\section{LAS IDEAS DE DIETER NOHLEN}

A. Dieter Nohlen sostiene que cambiar el sistema de gobierno en un país no es nada fácil porque implica lograr consensos difíciles de alcanzar ya que aquél es el núcleo de la parte orgánica de cualquier Constitución. Estoy de acuerdo con esta aseveración.

Por tal razón es más factible realizar una "adecuación funcional" a los sistemas presidenciales a través de "pasos institucionales y prácticos" de acuerdo con la realidad y la problemática de cada país, aunque existen factores comunes. En este supuesto lo que se persigue es "mejorar el funcionamiento del gobierno" introduciendo mecanismos que lo hagan más flexible, ágil y eficaz.

Los pasos prácticos, a los que este autor se refiere, son principalmente los que se alejen de la tendencia concentradora presidencial y sigan una "línea delegatoria en distintas funciones de gobierno y de administración". Lo anterior implica una fractura con la política concentradora que ha sido y es una práctica común de los sistemas latinoamericanos y de su cultura política, así como un rechazo al impulso que tiene cualquier presidente de esta región de aumentar sus poderes ante la debilidad que en múltiples ocasiones presentan los partidos políticos.

B. La propuesta toral de Nohlen para adecuar los sistemas presidenciales - especialmente los latinoamericanos - se encuentra en desconcentrar funciones del presidente en la figura de un primer ministro, aunque fuera por delegación presidencial.

Habría que tener en cuenta los diversos sistemas presidenciales así como las realidades en que ellos actúan, pero en América Latina, el primer ministro dentro del sistema presidencial tendría primordialmente tres finalidades:

a) Llevar la jefatura de gobierno, por delegación presidencial, principalmente la coordinación del gabinete y la supervisión de la administración del Estado. El presidente cumpliría sus atribuciones como jefe de Estado y estaría abocado a lograr consensos políticos y sociales por encima de las diferencias.

b) La función de enlace y negociación entre el Poder Ejecutivo y el Legislativo para superar posibles bloqueos mutuos entre ellos y lo ríspido de la lucha entre el partido del presidente y los de la oposición. 
c) La protección de la figura presidencial del desgaste cotidiano de la política, evitando el peligro de que el presidente sea el responsable de toda la política y de todos los problemas. ${ }^{32}$

Nohlen señala que en la discusión actual entre la conveniencia de un sistema presidencial o uno parlamentario en América Latina, está presente: a) una sobrevaloración del presidencialismo como un legado negativo, así como una sobrevaloración de lo positivo que sería tener un sistema parlamentario basado en el éxito que éste ha tenido en las democracias europeas, y b) la realidad multipartidista y las raíces ideológicas de los partidos y de las corrientes políticas que se acercan más a Europa que a los Estados Unidos.

C. En mi criterio, la propuesta de Nohlen es más factible que las examinadas de Linz y Sartori porque: a) por una parte, se basa en un conocimiento profundo de la realidad latinoamericana y lo difícil que sería alcanzar el consenso político para transitar a un sistema que nos es extraño pero guiados por el espejismo de que es un éxito en Europa occidental sin tomar en cuenta las abismales diferencias - por desgracia- políticas, sociales, económicas y culturales que nos separan de las democracias del viejo continente, y b) por la otra, elude experimentos políticos que tendrían altas posibilidades de fracasar.

Este autor es consciente de que los actuales sistemas presidenciales en América Latina tienen que ser innovados, rejuvenecidos o reformados; que pudieran permanecer tal y como hoy existen, no parece posible porque ya no responden a las aspiraciones democráticas actuales y en muchos casos se da un enfrentamiento o bloqueo entre los poderes políticos sin que existan instrumentos adecuados para su solución. En consecuencia, Nohlen hace una proposición fundamental: la introducción en dichos sistemas de la figura de un primer ministro aunque fuera por delegación presidencial.

Ahora bien, la introducción de un primer ministro o de un jefe de gabinete dentro de los sistemas presidenciales de América Latina, ha venido ganando adeptos y defensores. En principio es una idea que ya es norma constitucional en países como Argentina y Perú. 


\section{LA PROPUESTA DE ALONSO LUJAMBIO}

A. Las principales preocupaciones de Alonso Lujambio sobre estos temas se encuentran: en que "la gobernabilidad puede ser conquistada a través de medios más democráticos”, en que Linz tiene razón al afirmar que una democracia presidencial es intrínsecamente inestable, y en que no se contempla posible que México transite a un sistema parlamentario.

Por ello es indispensable — afirma este distinguido autor - realizar una serie de arreglos institucionales para lograr la estabilidad de una democracia presidencial en México con la finalidad de evitar parálisis políticas prolongadas.

Entre los aspectos que habría que revisar en nuestro país, Lujambio enumera: los poderes constitucionales del presidente, las funciones del congreso, el calendario de elecciones presidenciales y legislativas, la elección presidencial de mayoría relativa a una vuelta y el sistema federal. Asimismo hay que tener presente el número de partidos políticos y la disciplina que exista en ellos.

Este autor afirma que: "La combinación de un sistema de tres partidos disciplinados en el marco de un sistema electoral proporcional dentro de la esfera institucional del régimen presidencial de gobierno es una ecuación democrática posible para el México de hoy."

Lujambio propone reforzar la fórmula de representación proporcional en los escaños legislativos para que el presidente no cuente con una mayoría automática en el congreso y se vea obligado a negociar con los partidos de la oposición, primordialmente le preocupa la aprobación del proyecto de presupuesto. $^{33}$

Lujambio también sugiere otras reformas: aumentar a 5\% de la votación el porcentaje para que un partido político tenga derecho a representantes populares; si se suprimieran las elecciones intermedias de los legisladores, habría que acortar el periodo presidencial de seis a cinco años. Este agudo y claro autor analiza otros elementos para la estabilidad política de México, como la existencia de un número moderado de partidos, la influencia de un auténtico sistema federal en el régimen presidencial, su inclinación por la elección presidencial de una sola vuelta y los recursos para el patrocinio político. ${ }^{34}$

33 Carrillo, Ulises y Lujambio, Alonso, op. cit., p. 263.

34 Lujambio, Alonso, op. cit., pp. 94-105. 
B. Lujambio se aproxima a una corriente doctrinal que cada día tiene más defensores porque es realista, porque no cree en las "recetas", porque parte del examen del contexto social, político y económico del país. Se está inconforme con los defectos de nuestro sistema presidencial, aunque muchos de sus males no se encuentran en la estructura constitucional sino en vicios metaconstitucionales y en el sistema de partidos que hemos tenido en el cual uno de ellos ha poseído una especial hegemonía o predominancia.

Claro que se quiere y es imperativo poseer un régimen democrático fortalecido y renovado, sin los riesgos de los experimentos políticos. Por ello es que se afirma que lo mejor es la subsistencia del sistema presidencial pero reforzada su legitimidad y eficacia democráticas a través de reformas constitucionales para lograr un adecuado control del Ejecutivo por parte del Legislativo y cambios en costumbres y prácticas políticas y constitucionales viciadas. En esta corriente de pensamiento se encuentra Lujambio y ella es la más adecuada para nuestro país.

\section{El PENSAMIENTO DE DIEGO VALADÉS}

Las ideas han continuado afinándose y precisándose. Diego Valadés en su último y muy importante libro expresa con gran claridad las razones por las cuales es partidario de un sistema presidencial renovado o reformado. Comienza afirmando que cualquier sistema constitucional bien construido ofrece condiciones de gobernabilidad y que un sistema constitucional sólo es aquel que es democrático. Le asiste toda la razón.

Cuando se realizan cambios radicales — asienta - existe el riesgo de que, por la inexperiencia en el manejo de las nuevas instituciones así como por la resistencia al cambio de quienes las rechazan, los resultados no sean tan rápidos, efectivos y atrayentes como se esperaba. Con profundidad observa:

No sería necesario que se fracasara en el experimento parlamentario; bastaría con que los resultados se quedaran un ápice atrás de lo prometido o de lo deseado, para que se fortalecieran las tendencias de la restauración, que suelen convertir en virtudes los defectos de los antiguos regímenes.

Si de ese riesgo dependiera la única posibilidad de solución, habría que correrlo. Pero si la experiencia y la razón indican que hay otras salidas, y que es posible ahondar la ruta de la reforma adoptando y adaptando incluso mecanis- 
mos propios del parlamentarismo que, con buenas posibilidades de éxito, podrían injertarse en el presidencialismo, vale la pena intentarlo. Las limitaciones políticas de la suma cero, que han reducido la funcionalidad del sistema presidencial actual, pueden ser superadas.

La reforma que México requiere debe procurar: mejorar la funcionalidad de los órganos del poder; atender las demandas y las expectativas razonables de la colectividad, y restituir la confianza general en dichos órganos. Cualquier reforma que dificulte la funcionalidad de los órganos del poder tendrá efectos negativos para esos órganos y para la comunidad. La reforma debe hacerse, precisamente, para consolidar la eficacia democrática de las instituciones $\mathrm{y}$, por ende, recuperar la confianza ciudadana.

Si el diseño que se adopte es insuficiente, no se alcanzarán los objetivos de la reforma, y si es excesivo, desencadenará procesos de bloqueo en la acción de los órganos del poder, con la consiguiente frustración de las razonables expectativas generales de cambio.

En este contexto la reforma que se emprenda deberá tener los tres siguientes objetivos: reequilibrar las relaciones entre los órganos del poder; redefinir las funciones de los órganos del poder; y restablecer la legitimidad funcional del poder. $^{35}$

Valadés examina y enumera las causas por las cuales ciertamente el presidencialismo mexicano fue funcional durante décadas y las sintetiza en que preceptos programáticos de la Constitución los fue haciendo realidad.

En la actualidad — afirma - el caso mexicano debe concretarse en la transición de un sistema presidencial a otro sistema presidencial que consolide la democracia y reequilibre las relaciones de poder en nuestro país.

Para alcanzar esta nueva racionalidad del poder, Valadés propone una serie de reformas constitucionales como la reelección de los legisladores, el referéndum, las interpelaciones a los secretarios de Estado, la ratificación del gabinete por el Senado, el servicio civil tanto en el Poder Legislativo como en el Ejecutivo, la creación de organismos gubernamentales únicamente a través de la ley, el desenvolvimiento de nuevos órganos constitucionales autónomos, la ampliación de los periodos ordinarios de sesiones del Congreso, la duración de los periodos presidencial y legislativo, la presencia de un jefe de gabinete y la discusión y aprobación de iniciativas en bloque. ${ }^{36}$

35 Valadés, Diego, op. cit., pp. 412-413.

36 Ibidem, pp. 404, 409, 410, 416 y 418. 
Las iniciativas en bloque, que deben ser para casos excepcionales, son aquellas que el congreso aprueba o rechaza en "bloque", como una unidad, en virtud de que no pueden ser parcialmente alteradas o reformadas.

Valadés concluye con acierto que la transición del sistema presidencial mexicano se encuentra en el establecimiento de una nueva relación entre los órganos del poder, la cual deberá ser estable y duradera; es decir, que la misma no se esté continuamente alterando a través de reformas constitucionales.

El pensamiento de Valadés tiene el mérito de ser lúcido, concreto y propositivo. Al enumerar — tal y como también lo ha realizado Lujambio- una serie de propuestas para renovar nuestro sistema presidencial, colabora a elaborar la agenda de dicha renovación, a que se enlisten los temas que los mexicanos debemos discutir para consensar un nuevo sistema presidencial donde realmente funcionen los pesos y los contrapesos entre los órganos del poder; que el poder detenga al poder de acuerdo con la célebre, antigua y muy cierta oración de Monstesquieu.

\section{MANUEL ARAGÓN: "PARLAMENTARIZAR” EL SISTEMA PARLAMENTARIO}

La preocupación por la eficacia y el buen funcionamiento de un sistema de gobierno en el cual exista un verdadero equilibrio de poderes no se circunscribe únicamente a los sistemas presidenciales sino que exactamente la misma preocupación existe respecto a los sistemas parlamentarios en los países democráticos de Europa occidental.

Examino algunas ideas del distinguido tratadista español Manuel Aragón porque las mismas otorgan a la discusión una perspectiva más precisa que es útil en México. Toda comparación resulta injusta, pero las preocupaciones de Manuel Aragón respecto a los sistemas parlamentarios europeos son muy parecidas a las que se han expresado en este ensayo respecto al sistema presidencial en América Latina y específicamente en México.

Aragón nos dice que en Europa hay dos tendencias contradictorias respecto al sistema presidencial: una de crítica y rechazo que se dio principalmente en el periodo de entreguerras - y que aún subsiste- y otra de apreciación y emulación basada en la extensión del elemento personalista en la política, lo que se refuerza con el impacto televisivo, 
el liderazgo al interior de los partidos, el debilitamiento de los parlamentos y la forma de gobierno de la Unión Europea donde el protagonismo corresponde a los gobiernos. Todo lo anterior ha fortalecido a los poderes ejecutivos y ha venido creando en Europa un sistema de gobierno que respeta la estructura parlamentaria, pero que otorga la primacía indiscutible no ya al gobierno sino a la persona que lo encabeza, llámese canciller, primer ministro o presidente del consejo. En la realidad se ha dado una "presidencialización" de los sistemas parlamentarios aunque no un tránsito al sistema presidencial, sino un sistema híbrido en el que se conjuntan muchos de los inconvenientes de los dos sistemas y muy pocas de sus ventajas; lo que existe es un parlamentarismo distorsionado.

En este híbrido subsiste el control electoral por parte de la sociedad pero no los pesos y contrapesos que deben existir entre los órganos del poder en toda democracia, con lo cual se da una paradoja: el Legislativo puede ser más débil y el Ejecutivo más fuerte que en el mismo régimen presidencial.

El connotado catedrático de la Universidad Autónoma de Madrid indica que un sistema presidencial no puede funcionar sin un Legislativo fuerte, mucho menos lo puede hacer un sistema parlamentario y es por ello que en Europa resulta imperioso el fortalecimiento del parlamento para superar su atonía.

Los sistemas europeos de gobierno, entonces, necesitan imperativamente ser "parlamentarizados" porque en la actualidad, además, los medios masivos de comunicación y los tribunales de justicia ocupan el lugar central de la vida política en detrimento de los parlamentos.

Hay que fortalecer a los parlamentos, que vuelvan a ser el eje político del sistema. Aragón sugiere diversas medidas con este objetivo, entre las que menciona se encuentran: lo relacionado con el sistema electoral y la organización de las elecciones, la organización y el financiamiento de los partidos políticos, la organización y el funcionamiento interno de las cámaras y la dignificación institucional de la vida pública. ${ }^{37}$

La inquietud de Manuel Aragón y sus proposiciones son exactamente las mismas a las que me he referido en este ensayo y son las mismas que expusieron los tratadistas que he señalado: hay que fortalecer al Poder Legislativo, hay que conseguir una nueva relación entre los órganos del

37 Aragón Reyes, Manuel, Estudios de derecho constitucional, Madrid, Centro de Estudios Políticos y Constitucionales, 1998, pp. 282-283 y 302-311. 
poder donde exista equilibrio y pesos y contrapesos entre ellos, así como la conformación de un sistema de partidos que resulte eficaz en el funcionamiento del sistema político.

En otras palabras, la muy interesante exposición de Aragón nos hace ver que el problema no se encuentra en la existencia de un sistema parlamentario o de uno presidencial, sino en los aspectos mencionados en el párrafo anterior, aunque, desde luego, el sistema de gobierno es una pieza importante, pero sólo una, del conjunto del sistema político.

Un sistema de gobierno debe responder a la realidad y a las necesidades de un país, para reforzar y fortalecer ese equilibrio de poderes que es indispensable en cualquier régimen democrático, ya sea éste presidencial o parlamentario.

\section{MIS RAZONES Y MIS PROPOSICIONES}

A. De las páginas anteriores se desprende que a priori, en abstracto, el sistema parlamentario no es mejor ni más democrático, ni auxilia a conseguir un más adecuado equilibrio entre los poderes, ni ayuda más a la gobernabilidad de un país que el presidencial, y que estos sistemas funcionan, con la misma Constitución en forma muy diferente, de acuerdo con el sistema de partidos y electoral existentes en cada país.

El sistema de gobierno responde a factores y hechos políticos de cada Estado - aunque hay factores comunes-, a su evolución y madurez políticas, a sus costumbres constitucionales. No hay en este aspecto, reitero, "recetas", sino que hay que ser muy cuidadosos para que el sistema de gobierno sea acorde con las necesidades reales del país. Los principios generales de un sistema político deben ser afinados, ajustados, reformados e innovados de acuerdo con las realidades, necesidades y aspiraciones políticas de la comunidad.

Estoy de acuerdo, para México, con la corriente de pensamiento que representan Nohlen, Lujambio y Valadés y, como bien dijo este último, en nuestro país la transición debe ser de un sistema presidencial a otro sistema presidencial pero reformado o renovado.

Con base en reflexiones e ideas propias y en las expuestas por diversos autores reseñados en este ensayo, manifiesto, como síntesis, las razones de mi postura y mis proposiciones para alcanzar el sistema presidencial renovado o reformado, en el cual exista realmente un equilibrio de los 
órganos del poder, que los pesos y los contrapesos constitucionales funcionen correctamente, y que el sistema de partidos y electoral fortalezcan al sistema político para que continúe nuestra evolución democrática y el tránsito a un sistema político que elimine vicios y errores de décadas que han tenido como consecuencia un régimen autoritario, con algunos elementos democráticos, cuyo eje y columna vertebral ha sido el presidente de la República.

B. En México, estoy:

a) en favor de un sistema presidencial de gobierno,

b) en contra del presidencialismo,

c) a favor de un sistema presidencial renovado.

Trato de explicar mis anteriores afirmaciones.

a) Estoy en favor de un sistema presidencial de gobierno, porque:

i) la experiencia del derecho constitucional comparado demuestra que con él es posible lograr el equilibrio entre los órganos del poder, un control adecuado del Poder Legistativo respecto al Ejecutivo y el fortalecimiento de la democracia. Las actuales democracias en América Latina tienen como uno de sus fundamentos a este sistema de gobierno;

ii) es posible la negociación entre los poderes y, por tanto, la propia gobernabilidad;

iii) es el sistema que conoce la evolución constitucional de nuestro país, y en estos aspectos tan importantes para la estabilidad política no hay que andar haciendo experimentos teóricos. Ahí están los ejemplos de Estados con sistema presidencial que artificialmente pasaron a uno parlamentario y regresaron al presidencial porque la medicina resultó peor que la enfermedad. Un ejemplo es el caso de Brasil en tiempos de Goulart;

iv) no encuentro para México ninguna ventaja del sistema parlamentario sobre el presidencial. Al contrario, si realmente llegamos a configurar un sistema múltiple de partidos, el sistema presidencial garantiza mejor la división de poderes y los pesos y contrapesos entre ellos.

b) Estoy en contra del presidencialismo, porque:

i) es una degeneración del sistema presidencial en donde se avasalla a los otros poderes y se tiende al caudillismo y a la arbitrariedad;

ii) lesiona al régimen democrático al reducir a los actores políticos reales, concentrando las principales facultades en el Poder Ejecutivo; 
iii) generalmente el presidente ejerce funciones que le corresponden al Legislativo e incluso las que no le corresponden a ningún poder, sino al electorado;

iv) las libertades de las personas pueden peligrar porque en la realidad es difícil detener la arbitrariedad de los administradores.

En México, en las últimas décadas, no ha operado el sistema presidencial construido por la Constitución de 1917, sino una forma de presidencialismo que, como ya expresé, traté de analizar en mi libro $E l$ presidencialismo mexicano, editado en 1978.

A lo que llamo presidencialismo, Karl Loewenstein lo ha denominado neopresidencialismo cuyos rasgos relevantes son, de acuerdo con este autor, la existencia de un gobierno autoritario, la concentración de las atribuciones legislativas y ejecutivas en el presidente, y la subordinación del Legislativo al Ejecutivo; diferenciándolo de la autocracia por la existencia de procedimientos constitucionales. ${ }^{38}$

c) Estoy en favor de un sistema presidencial renovado, porque:

i) Nuestro país es hoy muy diferente del que conocieron los constituyentes de 1916-1917, quienes conformaron un sistema presidencial con los mecanismos clásicos de éste y sus controles respectivos, atribuyéndole amplias atribuciones al presidente de la República;

ii) es necesario lograr un mejor equilibrio de poderes del que actualmente estructura nuestra Constitución, dando algunos controles adicionales al Poder Legislativo, pero aclaro que no estoy en favor de un Ejecutivo débil ni que la predominancia del Ejecutivo la traslademos al Legislativo. Ni hegemonía ni superioridad de ninguno de los poderes sino equilibrio, pesos y contrapesos, entre ellos;

iii) es indispensable devolver a la sociedad y a los otros poderes, las facultades que el Ejecutivo federal les ha usurpado en los últimos decenios. Aquél sólo puede actuar con las facultades que expresamente le señala la Constitución y las leyes, y con ninguna otra;

iv) la sociedad mexicana desea perfeccionar y fortalecer nuestra democracia y al sistema político que está cambiando y que es imposible que vuelva a ser lo que fue. La sociedad no lo permitiría.

C. Dentro de este esquema de renovación de nuestro sistema presidencial, creo que deben realizarse una serie de reformas constitucionales; 
señalo algunas de las que considero que deben discutirse, porque no habrá de alterarse nuestra ley fundamental en este aspecto sino hasta después de una verdadera discusión nacional que exprese cuál es la voluntad de la sociedad mexicana. Sugiero que entre algunos de esos temas se incluyan los siguientes:

a) que el Congreso posea la atribución de ratificación de algunos de los nombramientos del gabinete presidencial, tal y como acontece en los Estados Unidos de Norteamérica;

b) la revisión de la facultad del veto presidencial para que no exista ninguna duda cuando el presidente de la República no posee esta atribución o con qué modalidad la tiene;

c) la introducción de la figura de jefe de gabinete de ministros, como acontece en Argentina a partir de 1994, quien es nombrado por el presidente de la República pero aquél es responsable políticamente ante el propio presidente y ante el Congreso nacional que lo puede remover con el voto de la mayoría absoluta de los miembros de cada una de sus cámaras; $;^{39}$

d) la revisión de las facultades legislativas del presidente de la República para precisar aspectos muy importantes, por ejemplo, si tiene atribución para crear organismos descentralizados y desconcentrados como lo ha realizado; los alcances de las normas sobre salubridad general expedidas por el Ejecutivo y la extensión de los "acuerdos ejecutivos" en el ámbito internacional;

e) la revisión del proceso legislativo para que en la nueva realidad política mexicana no vaya a darse una "parálisis legislativa", mucho menos respecto al proyecto de presupuesto. El derecho comparado puede ser muy útil en este aspecto, ${ }^{40}$

f) la creación de un verdadero y eficiente órgano de control dependiente del Congreso respecto a todas aquellas facultades que se refieren al "poder de la bolsa";

39 Pizzolo (h), Calogero, "Argentina y Chile. Dos modelos de presidencialismo", Boletín Informativo, Buenos Aires, año XIV, núm. 145, Asociación Argentina de Derecho Constitucional, 1998, p. 6; Nogueira Alcalá, Humberto, op. cit., p. 5.

40 Carrillo, Ulises y Lujambio, Alonso, op. cit., pp. 247-249. Diego Valadés en un artículo titulado “Agenda para la reforma del Estado", Excélsior, del 20 de julio de 1998, propuso: "7. Fijar reglas claras y predecibles para la aprobación del presupuesto. Una cosa es la discusión y definición de las políticas de gasto público y otra utilizar al presupuesto como amenaza política para desarticular el funcionamiento de las instituciones. El Estado democrático de derecho se debilita cuando periódicamente se cierne el peligro de la paralización total de las instituciones". 
g) la creación de cuerpos técnicos de alto nivel en diversas disciplinas que auxilien a los legisladores y a quienes se les asegure estabilidad en el trabajo para fomentar su experiencia. Desde luego serían cuerpos de técnicos apartidistas hasta donde ello es humanamente posible;

h) la revisión del sistema constitucional de responsabilidad del presidente de la República para que no vuelva a atreverse a ejercer funciones que no son suyas;

i) alguna fórmula que permita la reelección de los legisladores pero con ciertos límites, ${ }^{41}$ y

j) la introducción de mecanismos de gobierno semi directo como el referendo y la iniciativa popular. mi lista de temas que deberán de discutirse en el camino hacia un sistema presidencial renovado. 